\title{
Non Coronary Interventions In Contemporary Cardiac Practice
}

\author{
Savitri Shrivastava \\ Director \& Head, Deptt. of Congenital \& Pediatric Heart Diseases \\ Escorts Heart Instt. and Research Centre, New Delhi.
}

\begin{abstract}
SUMMARY
Catheter based techniques, whether palliative or corrective, are now the accepted therapy for many congenital cardiac defects. The spectrum of transcatheter procedures has rapidly increased over the last three decades with improving technical skills of the operator combined with sound anatomic and hemodynamic understanding of the patient's condition and the choice of appropriate equipments. In today's pediatric cardiology practice many congenital defects can be treated with balloons used for dilatation of the stenotic valves or vessels combined with the use of various stents for prevention of recurrence of stenosis, some defects can be closed with various devices or coils. With rapidly growing concepts, innovative hardware improvements, development and expertise of interventionalists and surgeons, the application of catheter interventions and hybrid procedures are becoming standard practice. Some of these are practiced in India. Many of them at present are not being practiced in India due to non availability of hardware and the prohibitive cost.
\end{abstract}

Correspondence : Prof. Savitri Shrivastava, Director \& Head, Deptt. of Congenital \& Pediatric Heart Diseases, Escorts Heart Inst. and Research Centre, Okhla Road, New Delhi-110025.

GLAXO ORATION delivered during NAMSCON 2012 at the Anna Centenary Library Convention Centre, Kotturpuram, Chennai. 
Catheter based interventions in pediatric population are an accepted modality of treatment in certain lesions. Sir William Rashkind was the pioneer to start the concept of therapeutic use of cardiac catheterization as early as 1966 (1). He increased the size of interatrial communication in a baby of classical transposition by forcefully pulling a latex balloon inflated with contrast media across the interatrial septum. This procedure of balloon atrial septostomy has saved many babies with transposition. In the last few decades the role of catheter interventions in the therapeutic management of congenital heart diseases has tremendously expanded. With the availability of balloon catheters and other gadgets that can be passed through 3 or 4 French sheaths, the field has also expanded into the neonatal age group. This has completely revolutionized the role of pediatric cardiologists in the cardiac catheterization laboratory.

These procedures could be curative, palliative or adjunctive to surgery. The procedures can be grouped under following headings:

1. Enlarging or creating an interatrial communication

2. Dilating obstructing valves/channels

3. Oc c luding a b norma 1 communications and channels

4. Unconventional.

Most pediatric catheter interventions are done in cardiac catheterization laboratory and require taking measurements of saturation, pressure and cine-angiograms. These procedures are done mostly under deep sedation or general anesthesia, appropriate equipment and manpower should be available for this in the cardiac catheterization laboratory. Before the procedure, a carefully done echocardiography study is essential for planning the interventional procedures. In some cases echocardiography imaging may also be needed during the procedure.

\section{ENLARGING OR CREATING INTERATRIAL COMMUNICATION}

\section{A. Balloon atrial Septostomy (BAS) :}

In 1966 Rashkind and Miller described this nonsurgical procedure to enlarge an atrial septal communication using a balloon catheter in a baby with classical transposition (Fig. 1). Since then its use has expanded for the initial management in many admixture lesions with restricted interatrial communication. Used primarily in babies under six weeks of age, balloon atrial septostomy has limitations in older infants, due to the increased thickness of the atrial septum. In these cases blade septostomy or static balloon dilation of the atrial septum are preferred to enlarge the interatrial communication (Fig. 2).

Although BAS is mostly a safe procedure, various complications have been reported in upto $11 \%$ of procedures in some series. These consist of rhythm disturbances like premature ectopic beats, supraventricular tachycardia, atrial flutter and fibrillation, partial or complete heart 

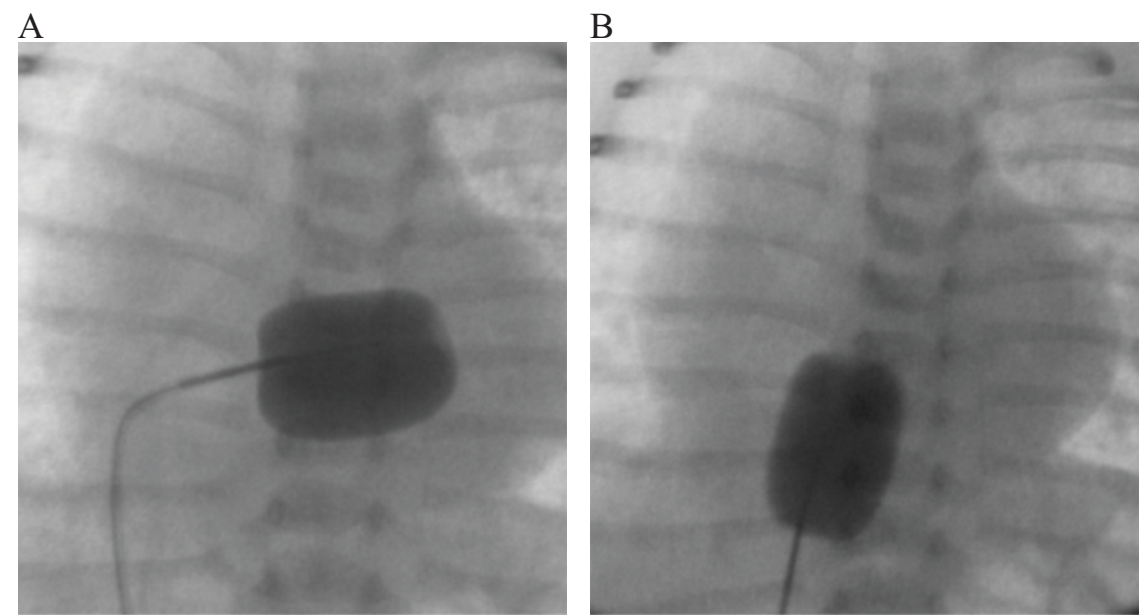

Fig. 1: Antero-posterior view

A.Balloon across the patient foramen ovale PFO into left atrium LA B.Balloon pulled across the PFO fully inflated into RA
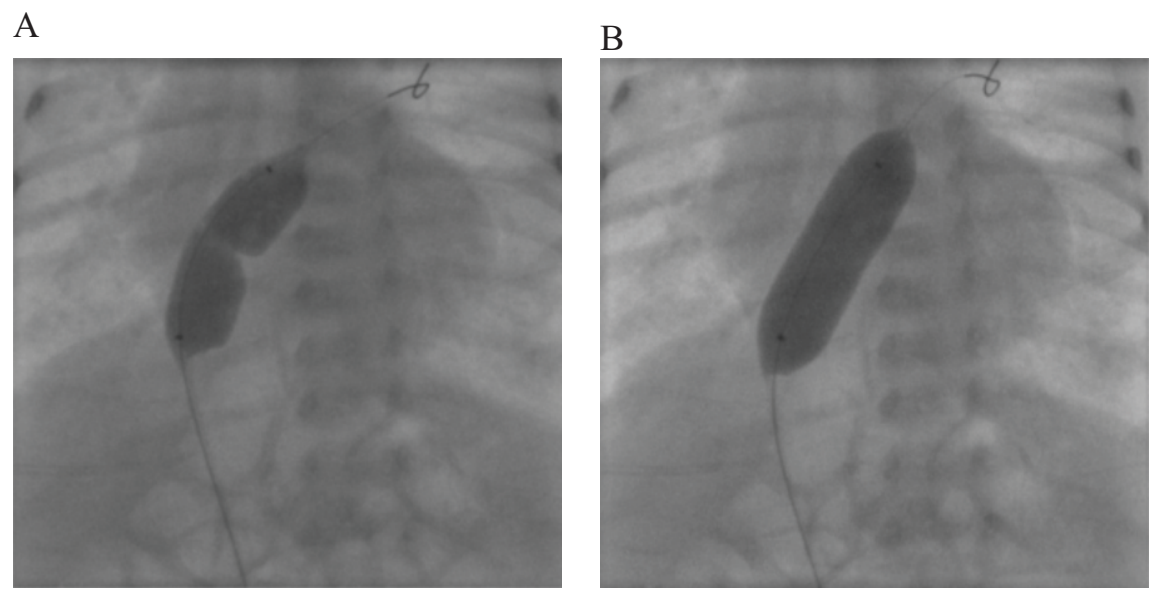

Fig. 2: Antero-posterior View

A.Static Balloon across the atrial septum B.Fully inflated balloon

block, ventricular arrhythmias, perforation of the heart, balloon fragment embolization, laceration of atrioventricular valve, systemic or pulmonary veins and failure of balloon deflation.

\section{B. Blade atrial septostomy :}

In older infants above 6 weeks of age blade atrial septostomy with Park blade catheter (2) can be done for the same indications as for balloon atrial septostomy. Although this technique has 
had good success rates, ranging from $70 \%$ to $90 \%$, it can cause fatal complications especially when the left atrium is small (3) as such this technique is not routinely used.

\section{Static Balloon Dilatation :}

Balloon dilatation done after transseptal placement of a guidewire can be effective in enlarging an atrial septal communication. The resultant defect will be somewhat smaller than the balloon used for dilation so an oversized balloon is desirable to use. Balloons three to four times of the size of the interatrial communication are generally used for dilatation of the atrial septum $(4,5)$.

\section{Radiofrequency Ablation (RFA) :}

Rarely the atrial septum is imperforate and in these babies the initial opening is created by RFA at the site of patent foramen ovale and later it is dilated with a balloon.

\section{DILATING OBSTRUCTED VALVES OR CHANNELS}

\section{A. Balloon dilatation of pulmonary valve:}

Balloon dilatation of pulmonary valve using a noncompliant balloon was first reported by Kan et al in 1982 (6). The technique has been successfully used in patients of all age groups from the newborn period to adult life. With its excellent results and low rate of procedure related complications, maximum instantaneous systolic Doppler gradients of as little as $35 \mathrm{mmHg}$, when combined with evidence of right ventricular hypertrophy, should be considered for balloon pulmonary valvuloplasty (Fig. 3). The optimum balloon diameter should be between 1.2 and 1.3 times the size of the pulmonary valve annulus for singleballoon dilation $(7,8)$. Lower balloon-to-
A

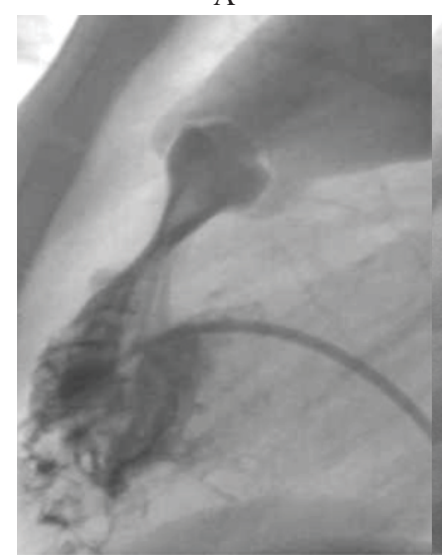
B

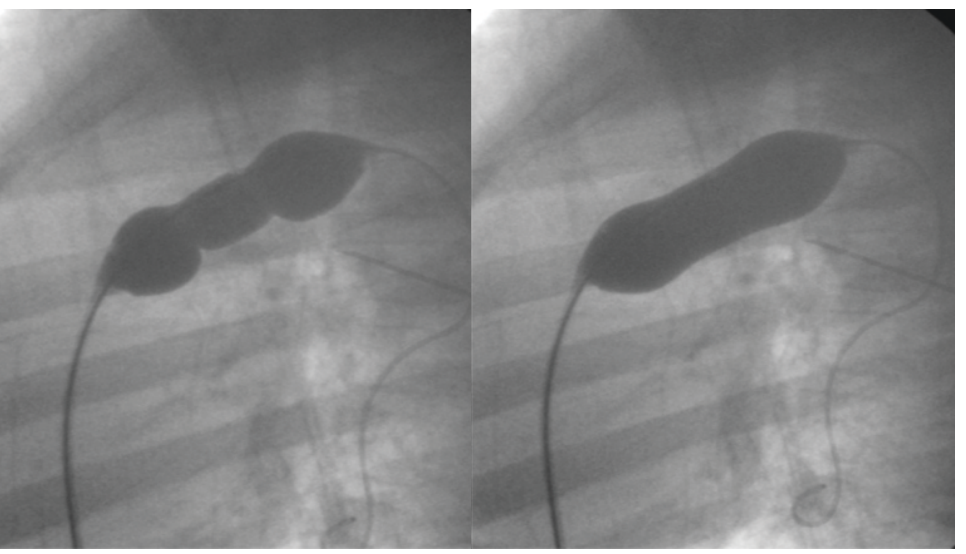

Fig. 3: Lateral view showing A.RV angiogram showing severely stenosed pulmonary valve B. Balloon across the pulmonary valve, C.Balloon fully inflated to relieve the obstruction 
valve annulus ratios are associated with residual pulmonary valve stenosis and/or an increased risk of recurrence, whereas ratios of 1.4 or above are associated with an increased risk of clinically significant pulmonary insufficiency.

Balloon dilatation of pulmonary valve produces long term gratifying results, and re-stenosis rates are extremely low except in neonates. Restenosis rates of between $5-11 \%$ have been reported on 10 years follow up $(9,10)$.

\section{Balloon Dilatation of Neonatal Pulmonary Stenosis or Valvar Atresia}

This is a special subset of patients with pulmonary stenosis. They are duct dependant and also require careful assessment of the right ventricle size by echocardiography in order to assess potential for normalization of ventricular size, which finally determines whether the patients will have a single or biventricular repair. In critical pulmonary stenosis and valvar pulmonary atresia in neonates the right ventricular outflow tract is oriented posteriorly instead of superiorly. The right coronary catheter $(4 \mathrm{~F}$ or $5 \mathrm{~F}$ ) is better suited to cross the pulmonary valve. Some authors use a $5 \mathrm{~F}$ coronary guiding catheter to achieve a stable position beneath the pulmonary valve. The advantage of this technique is that the initial balloon dilation of the valve can be done with the guiding catheter is position. The atretic valve in these cases has to be perforated by a radiofrequency catheter in order to gain access to the pulmonary artery (11).

\section{B. Balloon dilation of Aortic Valve :}

Balloon dilatation of stenotic aortic valve is now procedure of choice in most patients of aortic valvar stenosis in pediatric and adolescent age group (Fig. 4). In comparison to dilatation of pulmonary valve, balloon dilatation of aortic valve is more difficult and less gratifying. Aortic valvuloplasty is usually palliative and not infrequently aimed at
A

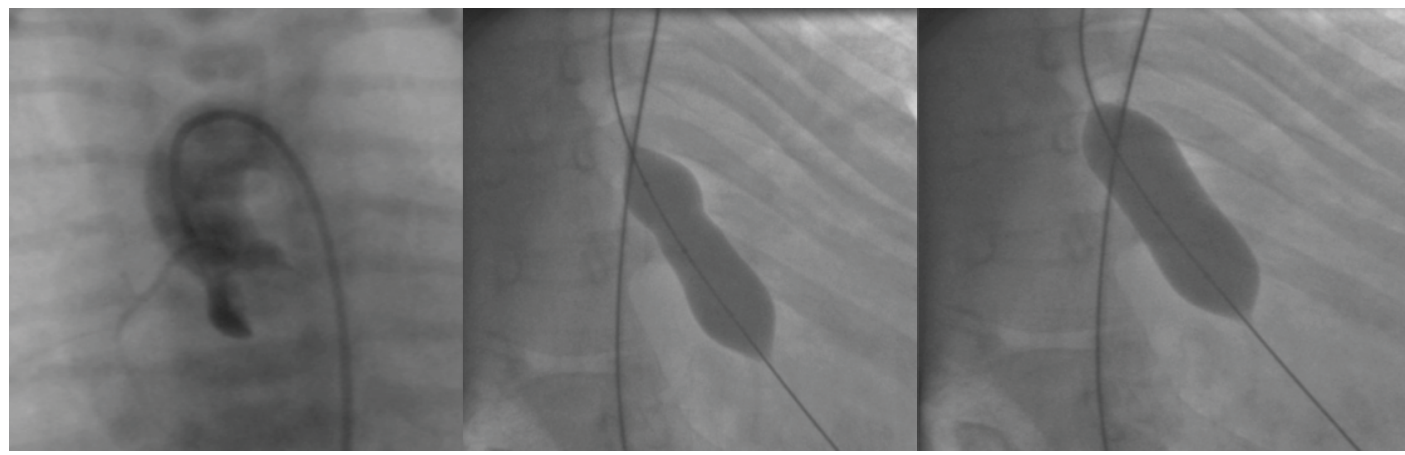

Fig. 4: Right anterior oblique view

A. Aortic root angio showing doming stenosed aortic valve

B. Partially inflated balloon across the aortic valve

C. Fully inflated balloon across the aortic valve 
delaying an inevitable surgical procedure, be it valve replacement or a Ross procedure, until a time when the child has reached close-to-adult size.

Guidelines for the treatment of congenital aortic valve stenosis in children are where a peak-to-peak gradient $>60 \mathrm{mmHg}$ and mean gradient is $>45 \mathrm{mmHg}$ in asymptomatic patients in presence of normal left ventricular function. In presence of left ventricular dysfunction occurring as a result of aortic valve stenosis or symptoms, the gradients become irrelevant and balloon dilatation of aortic valve should be done even if the gradients are less. The balloon diameter used is $90 \%$ of the aortic annulus. With dilation of the aortic valve, the gradient should be reduced by $60 \%$ to $70 \%$ or to a gradient $<30$ to $40 \mathrm{mmHg}$. This usually can be accomplished without inducing significant aortic insufficiency, no more than that seen after surgical valvotomy. The long term results, like surgical valvotomy, will be palliative; however, the catheter balloon dilation procedure is accomplished without a sternotomy or cardiopulmonary bypass with their inherent risks and morbidity $(12,13)$.

\section{Balloon dilation of Discrete Subvalvular Membrane (DSS) :}

Thin membranous (1-3 mm) DSS can be effectively and safely dilated with Balloon percutaneously without production of significant aortic regurgitation. These patients remain intervention free in long term follow up. In case there is restenosis, they can be redilated with balloon(14).

\section{Balloon dilation of Coarctation of Aorta :}

Fierce controversy still rages on the best method to treat coarctation of aorta. This is because of the complex nature of the lesion and the varied presentation. The lesion can be classified as below:

\section{Native coarctation}

- Neonatal

- Older children

- $\quad$ Adolescent/Adult

\section{Recurrent coarctation}

Classifying according to age of presentation is useful because it may determine the type of therapy $(15,16)$.

\section{Native Coarctation:}

\section{Neonatal and infantile coarctation}

The role of balloon dilatation of native coarctation in infants remains controversial despite 20 years of experience. There is a high risk of restenosis in neonates and infants upto 6 months with the recurrence rates approaching $100 \%$ within 6 months. It is desirable to refer such patients for surgical correction except in those patients who present with shock and severe ventricular dysfunction in whom an initial balloon dilatation may be offered due to high surgical risk. 


\section{Babies $>6$ months}

Though in this group of children recurrence is less common, residual gradients are an issue but they are similar to that after surgery. Aneurysm formation has been reported in $5 \%$ of patients. In general, results of balloon dilatation are better if there is a localized coarctation, rather than long segment coarctation or associated arch hypoplasia. Children above 9 years could be considered for stenting of the coarctation.

\section{Adolescent and Adults}

In the majority of cases balloon dilatation with or without stent is offered as the first choice of treatment. Restenosis is comparable to surgery. Better abolition of gradients is seen with use of stents. Covered stents may have to be used if there is significant dissection or aneurysm formation in the post dilatation angiogram $(17,18,19)$ (Fig. 5).

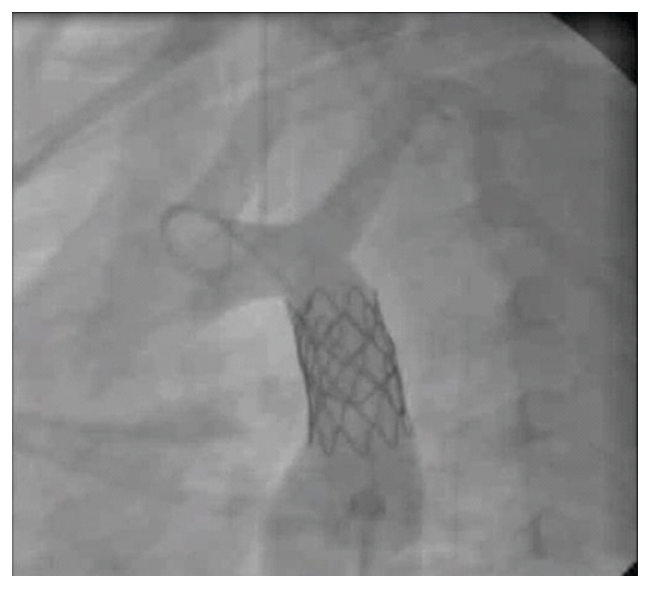

Fig. 5: Left lateral view showing stent placed in coarcted segment of aorta

\section{Recurrent Coarctation :}

There is a consensus that recurrent coarctation should be treated by balloon dilatation and stenting in the absence of significant arch hypoplasia.

\section{E. Balloon dilation and stenting of pulmonary arteries :}

Branch pulmonary artery stenosis is often seen as a residual or recurrent problem in patients with Fallot's tetralogy or pulmonary atresia having undergone total repair. It may also be seen as isolated lesion in certain group of patients such as William's syndrome, Allagile syndrome etc. These lesions, usually solitary (multiple in syndromic patients) are often difficult to dilate and require highpressure balloons. There is also a risk of dissection at the time of dilatation. The lesions are often fibrotic and restenosis is quite common. Cutting balloons often give better outcome as compared to simple balloons. With standard balloon angioplasty few of the dilated vessels are maintained at a normal diameter. The true success rate of achieving a vessel of normal diameter with no gradient is $<20$ $\%$. At the same time, there is a definite morbidity and even mortality for the procedure. In view of these problems associated with balloon dilatation, stent implantation has been used to open up stenotic pulmonary arteries with $90 \%$ success rate and low incidence of restenosis (20) (Fig. 6). 


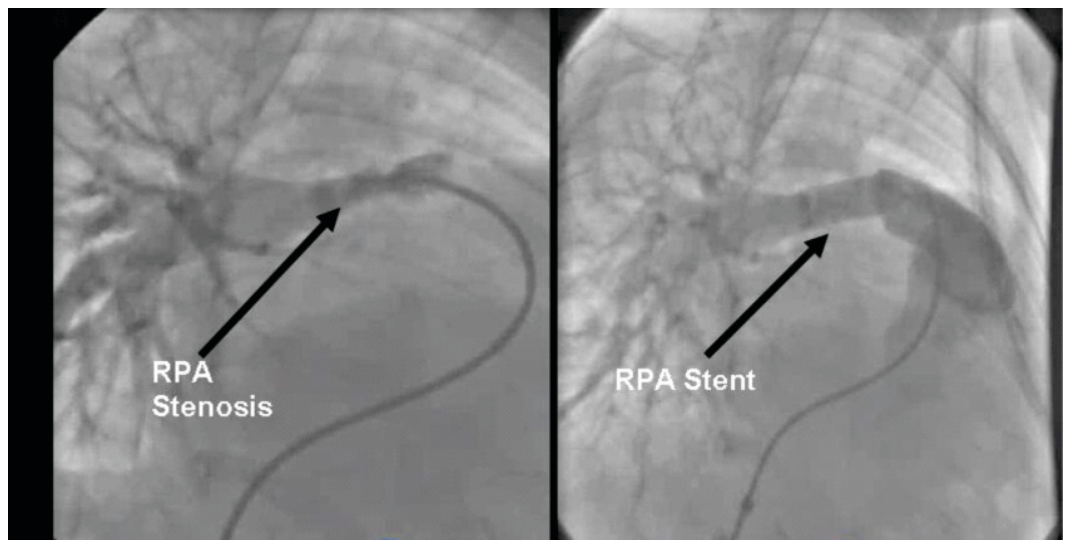

A

B

Fig. 6: Antero-posterior view with cranial angulation A.Showing stenosis at origin of right pulmonary artery (RPA)

B.Stent placed to open up the right pulmonary artery

\section{CLOSURE OF CARDIAC DEFECTS AND CHANNELS}

\section{A. Closure of Patent Ductus Arteriosus (PDA):}

Coil occlusion and device closure of patent arterial ducts are widely accepted practice.

\section{Coil Closure of PDA}

If the PDA size is less than $2.5 \mathrm{~mm}$, the PDA can be successfully closed by placing Gianterco coils percutaneously with the help of bioptome (Fig. 7). The success rate of the procedure is $95 \%$ with minimal complications. Before introduction of the Amplatzer duct occluder, many moderate to large sized PDAs were occluded using multiple coils $(21,22,23)$.

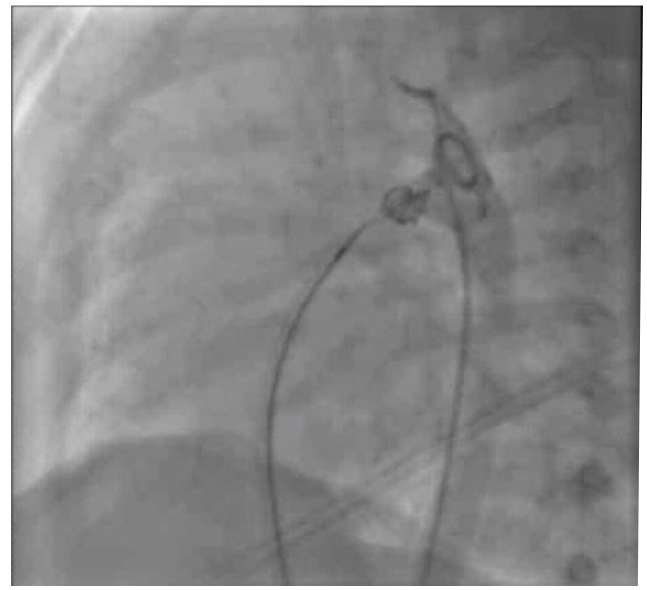

Fig. 7: Left lateral view Patent Ductus Arteriosus closed by Gianterco Coil placed with help of Bioptome

Device closure of PDA

If the PDA is bigger than $2.5 \mathrm{~mm}$, it is better closed by Duct occluder (Fig. 8). The device is available in various sizes. The optimum device size is chosen after the standard aortogram in such a way that 


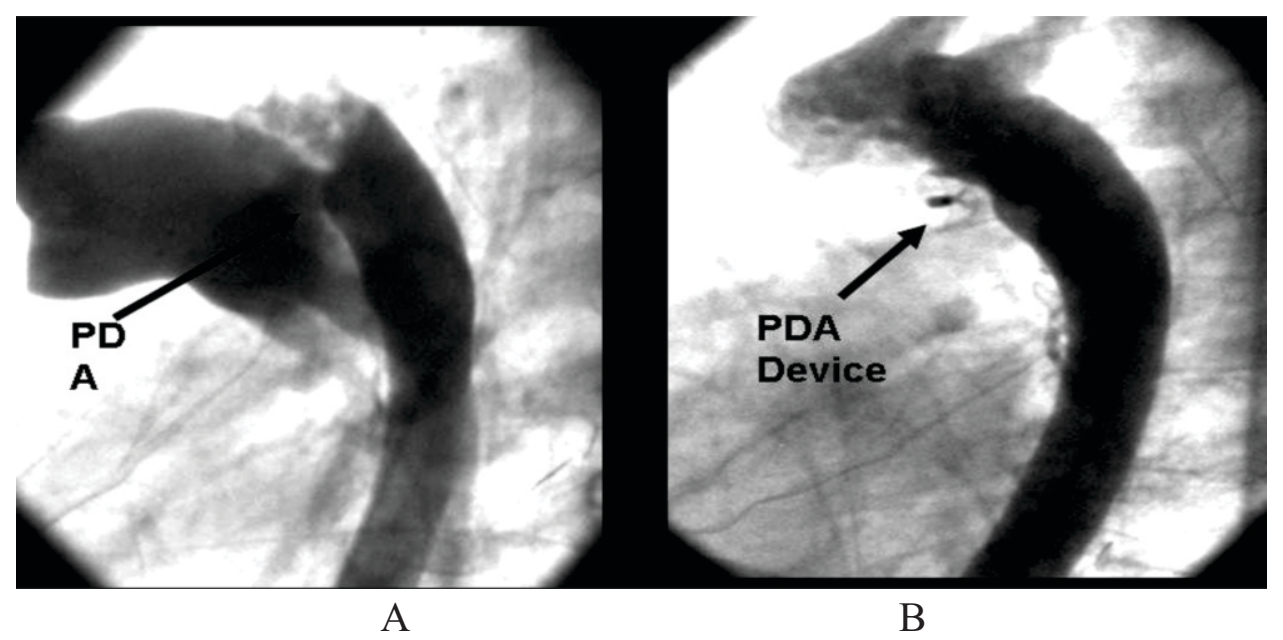

Fig. 8: Left lateral view

A. Showing a large PDA

B. Closure of Patent Ductus Arteriosus done by PDA device

the pulmonary end is $2 \mathrm{~mm}$ larger than the narrowest duct diameter. For larger arterial ducts with reversible pulmonary hypertension, one may up-size the device to next available larger size. The device closure can be successfully done in babies $>5 \mathrm{~kg}$. The results of device closure of PDA are excellent, $100 \%$ closure by 3 months. The complication rates are less than $1 \%(24,25)$.

\section{B. Closure of Atrial Septal Defects (ASD) :}

Surgical closure of ASD remains gold standard, however catheter based device closure is possible in selected patients, with fossa ovalis type of defects. A careful echo evaluation for the size and type of ASD done transthoracically or transesophageally in adolescent and adults or in patient with poor Echo windows helps in selecting a suitable patient. Single centrally placed defects with good margins all around (at least 5 $\mathrm{mm}$ ) are considered most suitable for device closure. A variety of devices are available for the purpose, but Amplatzer septal occluder has been most widely used $(26,27)$ (Fig. 9). It is double disc device, made of Nitinol. The device is selfcentering, and is available in a range of sizes. It has the potential to close ASD of anatomical sizes up to $38 \mathrm{~mm}$. The intermediate and long term follow up (up to 10 years) show excellent closure rates (>98\% closure rates) $(28,29,30)$.

\section{Complications of ASD device Closure}

Complication rates for ASD device closure are less than 1\%. Embolization of the device is the most common complication seen most often during attempts to close large ASD's. Embolization to right sided circulation, left atrium, left ventricle have all been reported. Retrieval of the device can be 


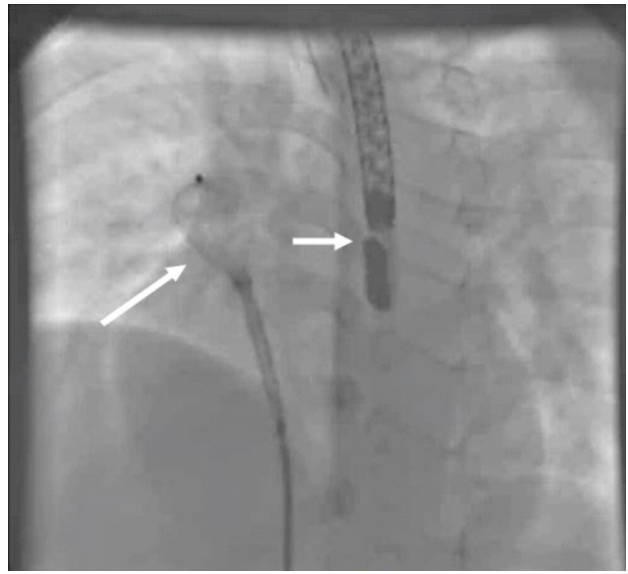

A

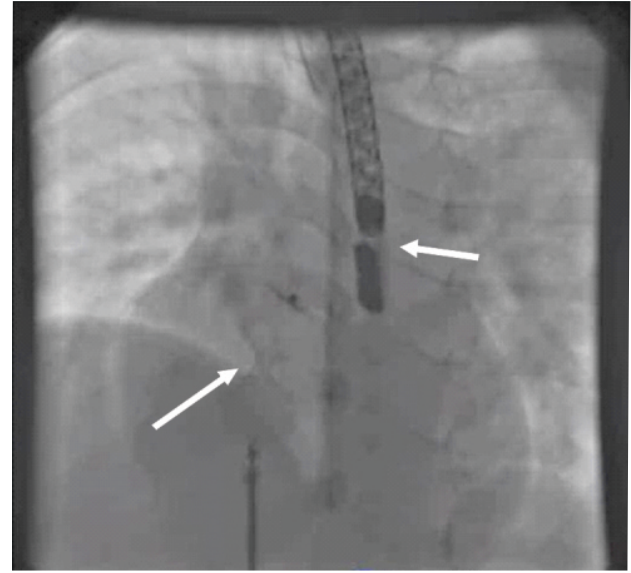

B

Fig. 9: Antero-posterior view

A.Showing ASD device with delivery cable in Left atrium antero-posterior (Large arrow). TEE probe (Small arrow). B.Left anterior oblique view showing deployment of the device (Large arrow) across the atrial septal defect.

TEE probe (Small arrow).

done with snare but a large percentage of patients may have to undergo surgical retrieval.

Malposition of device across the atrial septum - this can be avoided by careful attention to details on TEE before release of device.

Erosion by device into adjacent structures - this is a rare complication. The commonest site reported is the aorta where the device straddles followed by roof of atria.

\section{Closure of Ventricular septal defects (VSD):}

Closure of the ventricular defect in the catheterization laboratory still remains a challenge. Most defects that need closure in pediatric age group are large, and need to be closed in early infancy. Hence surgery remains the of choice procedure.

Device closure can be done in selected group of patients with muscular ventricular septal defects $(31,32)$ and residual VSD after surgery. Device closure of perimembranous ventricular septal defects, though feasible, has resulted in heart block in some cases on follow-up hence remains controversial. A meta analysis of 1569 cases showed a complication rate of $11.73 \%$ (33). Moderate size muscular defects either denovo, residual or acquired after myocardial infarction are considered technically suitable for catheter based intervention $(34,35)$. Amplatzer devices 


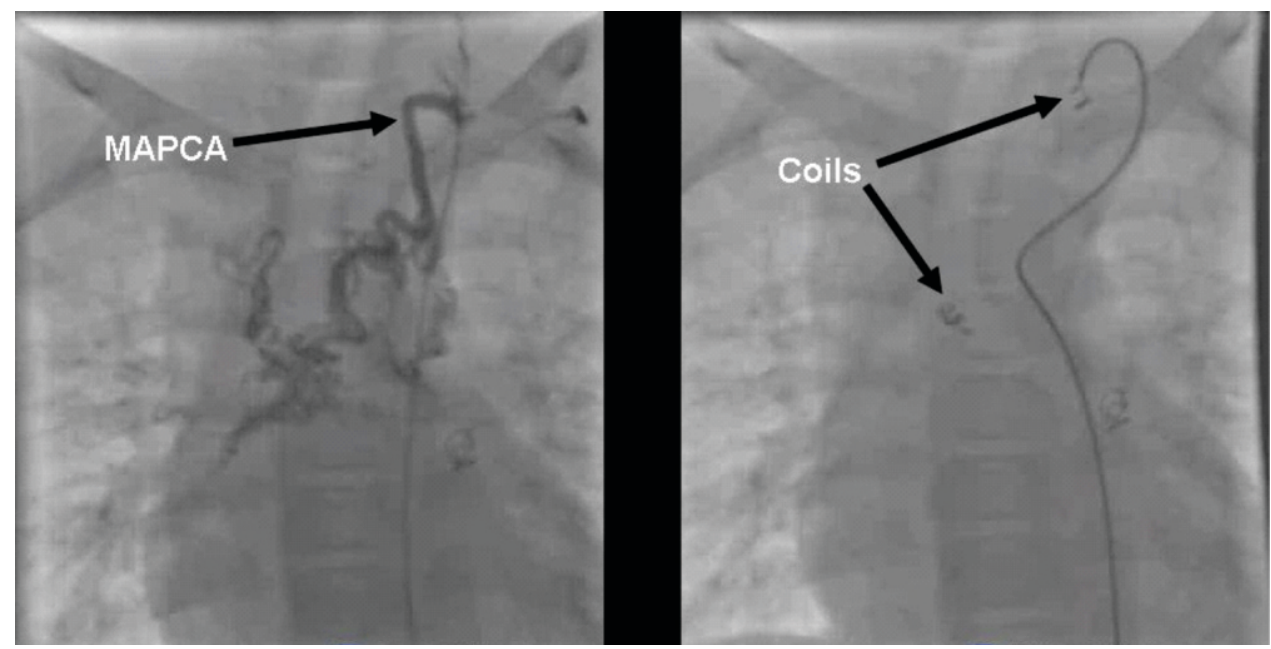

A

$\mathrm{B}$

Fig. 10: Antero-posterior view

A.Selective catheterization of one large aorto - pulmonary collateral (MAPCA) B.Coil closure of the MAPCA

have been used widely for the purpose.

It is important that after positioning the device across the ASD/VSD, before its release, following are carefully evaluated - encroachment over adjacent structures such as SVC, IVC or pulmonary veins, mitral regurgitation, pericardial effusion, atrial or aortic leaks, clots, increase in pulmonary artery pressure. In event of any of these the device should not be released.

Difficult to approach muscular VSD are also now being closed by device during the surgery as hybrid procedures. The device is delivered periventricularly, through the RV free wall. The procedure is still in infancy and with installation of fluoroscopy in pediatric cardiac surgical suits, this will probably become the procedure of choice in many cases.

\section{Closure of Aorto pulmonary collaterals:}

In any busy congenital heart disease unit treating complex cyanotic congenital heart diseases, catheter closure of aorto pulmonary collaterals forms a large percentage of interventional procedures being performed. The logic of closing these lesions is two fold:-

- To prevent excess return during cardio pulmonary bypass.

- It can be a source of intra pulmonary bleed during the postoperative phase (36).

These collaterals can be easily closed by using Gianterco coils with almost $100 \%$ success and very low complication rates (Fig. 10). 
E. Closure of venovenous collaterals:

Patients with complex congenital heart disease having undergone the Glenn procedure may develop progressive desaturation. One important cause for this is enlargement of existing connecting venous channels between the superior vena cava and Inferior vena cava. Of these, the azygos or hemiazygos are the most common. These decompressing venous channels contribute to systemic desaturation. Conversion to the Fontan automatically "solves" this problem as finally all desaturated blood (upper and lower limb) reaches the pulmonary circulation. If however the hemodynamics and age of the patient do not permit conversion to Fontan, then closure of these channels may improve systemic saturation. This procedure is best performed non-surgically. The decompressing channel is easily accessed from the jugular or subclavian vein. After engaging these channels, coils, vascular occlusion device or combination can be used to occlude these channels (37) (Fig. 11).

\section{F. Closure of Ruptured sinus of Valsalva :}

Though the most definitive treatment of ruptured sinus of valsalva is surgical correction; in highly selected cases percutaneously delivered device have been used to occlude the ruptured aneurysm. The device used is Amplatzer septal occluder (38).

\section{G. Pulmonary AV Fistula :}

Coil/Septal Occluder/vascular occlusive devices have all been used to close pulmonary AV fistulas and are the

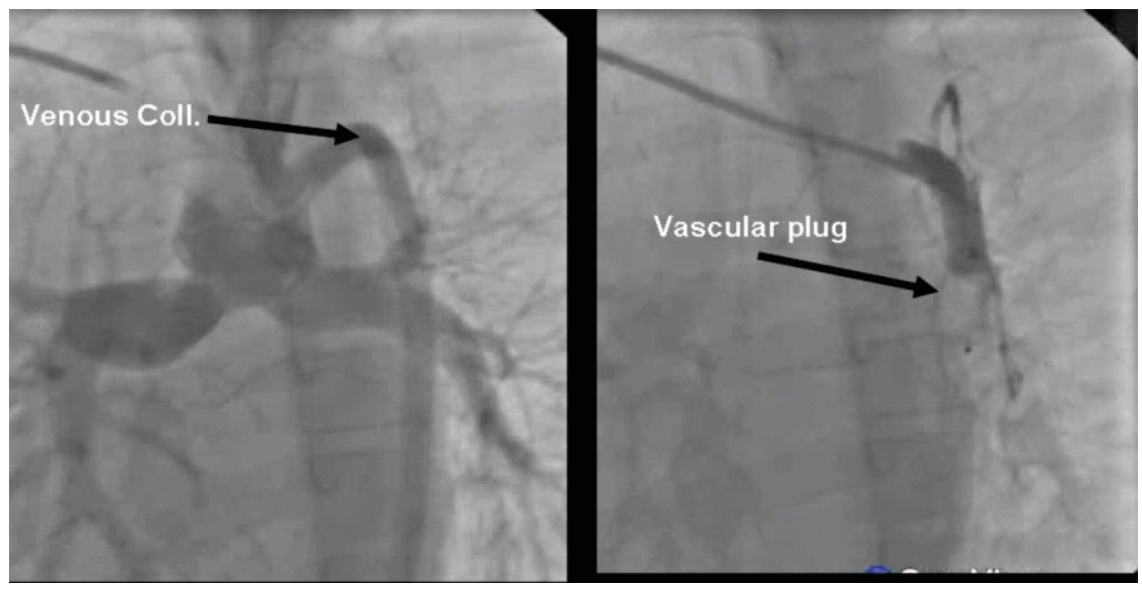

A

B

Fig. 11: Antero-posterior view

A.One large veno - venous collateral after Glenn shunt C

B.Closed by vascular plug 


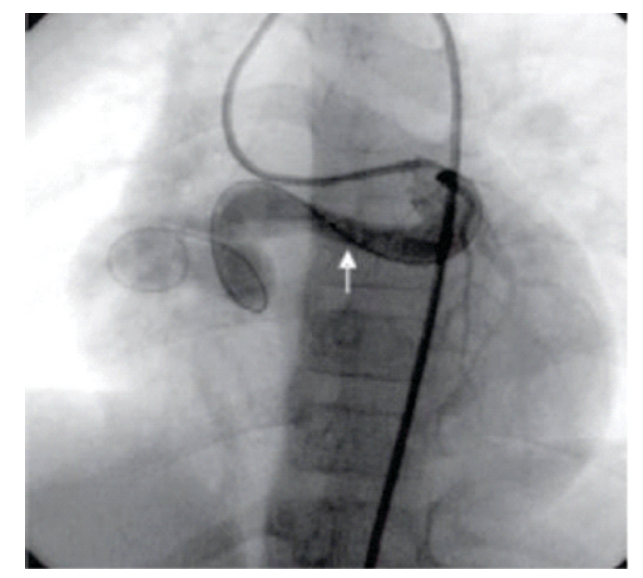

A

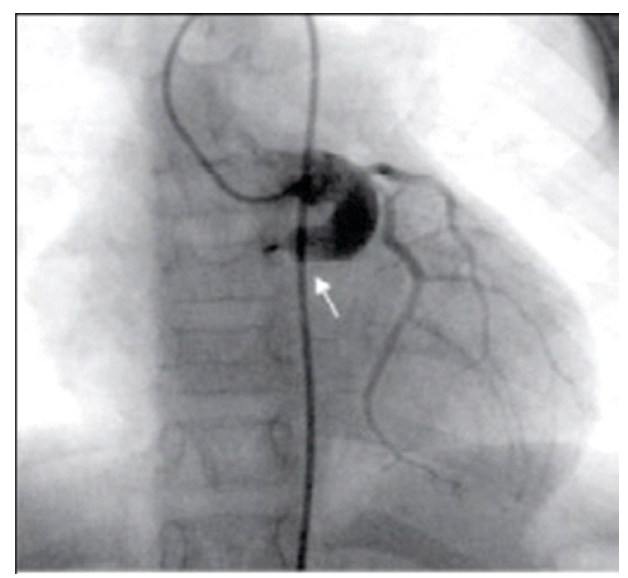

B

Fig. 12: Antero - posterior view

\section{A.Coronary - cameral fistula from left circumflex artery to right atrium (arrow) B.Closure of the coronary-cameral fistula done by vascular plug (arrow)}

treatment of choice in the localized (single or multiple) variety $(39,40)$. The results are judged by the immediate rise in saturations as the fistula is blocked.

\section{H. Coronary AV Fistula :}

Non surgical closure of coronary AV fistula is the treatment of choice. Depending on the size of communication, coils or devices (vascular occlusion device, PDA device) (Fig. 12) can be used to close the communication $(41,42)$.

\section{Unconventional uses of Septal Devices :}

At present closure of certain non septal defects with devices conventionally used for cardiac septal defects is being done successfully. Some of the devices are being used for closure of defects which were not originally meant to close those defects.

\section{Aorto Pulmonary Window (AP window) :}

Small AP windows can be closed by patent duct occluders. Care needs to be taken that after placing the device the right pulmonary artery flow and the left coronary artery flow is not compromised and the device does not interfere with the closure of aortic valve. Some series have shown that $10 \%$ cases of AP windows could be suitable for device closure.

\section{Amplatzer Duct Occluder II :}

This is a modified duct occluder device for unusual duct anatomy particularly long tubular and angulated PDA. As it is more flexible, this device is being successfully used to close muscular VSDs and some of the perimembranous VSDs (43). In muscular VSDs, as it is more flexible, it conforms easily to the 
unusual tracts of muscular VSDs. In small perimembranous VSDs because of its flexibility it is less likely to cause heart block which was a complication with Amplatzer VSD device used to close perimembranous VSDs and many centres including ours had abandoned its use. The initial results with ADO II are encouraging. However long term results are awaited.

\section{PDA stenting in duct dependant lesions in new born and infants (44) :}

In cyanotic babies with markedly reduced pulmonary blood flow, conventionally Blalock Taussing shunt is done to increase the pulmonary blood flow and reduce the cyanosis. Now a days in many centres including ours, stenting the patent ductus arteriosus to increase the pulmonary blood flow is being used.

\section{Stenting of Right Ventricular outflow tract :}

In infants and children with subvalvular right ventricular outflow obstruction stenting is being used to open the out flow tract.

\section{Interventions in pipeline :}

Interventions which are being done in USA and Europe but due to hardware non availability and cost, we are not yet doing these in India.

\section{Percutaneous pulmonary valve implantation :}

This technique is very useful in effectively treating right ventricular out flow tract conduit stenosis and free pulmonary regurgitation resulting in right ventricular dilatation in patient operated for TOF physiology. This avoids second open heart surgery. Medtronic Melody valve is most commonly used (45). Late restenosis in short term follow up is not significant. Complication in terms of coronary compression and stent fracture (treated by insertion of second stent) have been noted. However the durability has not been tested in humans due to lack of long term data. The cost remains prohibitive.

\section{Fontan Completion by Catheter Intervention (46) :}

In patients of univentricular physiology, Fontan completion surgery is done after the initial palliative Bidirectional Glenn (BD Glenn) Surgery. In some of these patients in early infancy, a Blalock Taussing Shunt or pulmonary artery banding is also needed. Presently in some centres, a lateral tunnel is created at time of BD Glenn. The atrial end of superior vena cava is closed by a patch. The aperture of lateral tunnel is kept larger than the Inferior vena cava diameter. At the time of Fontan completion, the SVC patch is perforated by a RF catheter and stent is placed at SVC - Atrial junction. The aperture is closed with atrial-septal occluder. This procedure results in less pleural effusions and arrhythmias compared to surgical Fontan completion. Additionally there is a potential for successive dilation of Fontan pathway created percutaneously to accommodate for growth. 


\section{Hybrid Procedures :}

Procedures in which the pediatric cardiac surgeon and the cardiologist work together in an area where the facilities of operation theatre and the angiocardiography are available in the same room. The Echocardiography and in some places the MRI equipment is also available in the same area. Thus it needs very highly specialized and costly infrastructure. Unusually located muscular VSDs can be closed by putting the Device perventricularly. The VSD closure and pulmonary artery stenting can be done simultaneously, larger size of stent can be placed irrespective of patient size, limited vascular access. Stent could also be placed for recurrent coarctation of aorta, across Fontan Fenestration, right ventricular out flow tract.

\section{Fetal Cardiac Interventions (47):}

Since last two decades various centres in USA, UK, and Europe have been trying Fetal Cardiac Interventions. Limited success has been reported in few lesions - like severe aortic stenosis, pulmonary stenosis, restrictive foramen ovale, closing patent ductus arteriosus. However this procedure needs the collaboration of highly specialized team of pediatric cardiologist, obstetrician, anesthetist, Echocardiography consultant, nurses and technicians. Also it needs highly specialized equipment. The results do not seem to be so gratifying.

\section{Summary:}

Therapeutic cardiac catheterization represents significant advance in care of patients with congenital heart disease. There are many cardiac lesions, which can be either corrected or palliated without an incision or putting the patient on cardiopulmonary bypass by these percutaneous techniques. The short hospital stay and lower indirect cost of therapy have led to their wide acceptance. Recently therapeutic cardiac catheterization has advanced beyond the confines of catheterization laboratory and many hybrid procedures are done with cooperation between interventional cardiologist and cardiac surgeon.

\section{REFERENCES :}

1. Rashkind WJ, Miller WW (1996). Creation of an atrial septal defect without thoractomy: a palliative approach for complete transposition of the great arteries. JAMA 196:991992.

2. Khan A, Bricker T, Mullins CE, Al Yuosef S, Nihil MR, Vargo TA (1991). Blade atrial septostomy: experience with the first 50 procedures. Cathet Cardiovasc Diagn 23: 257-262.

3. Park SC, Neches WH, Zuberbuler JR, et al. (1978). Clinical use of blade atrial septostomy. Circulation 58: 600-606. 
4. Rao PS (1993). Static balloon dilatation of the atrial septum. Am Heart J125: 1824-1827.

5. Shrivastava S, Radhakrishnan S, Dev V, Singh LKS, Rajani M (1998). Balloon dilatation of atrial septum in complete transposition of great arteries - A new technique. Indian Heart J 39: 298-300.

6. Kan JS, White R1 Jr, Mitchell SE, et al. (1982). Percutaneous balloon valvuloplasty: A new method for treating congenital pulmonary-valve stenosis. $N$ Engl J Med 307: 540 524.

7. Shrivastava S, Mukhopadhya S (1986). Non surgical treatment of pulmonary stenosis. Indian Pediatr 23: $107-111$.

8. Shrivastava S, Shyam Sunder A, Mukhopadhyay S, Rajani M (1987). Percutaneous transluminal balloon pulmonary valvuloplasty long term results. Int J Cardiol 17: 303-314.

9. Stanger P, Cassidy SC, Girod DA, et al. (1990). Balloon pulmonary valvuloplasty: Results of the Valvuloplasty and Angioplasty of Congenital Anomalies Registry. Am J Cardiol 65: 775-783.

10. Jarrar M, Betbout F, Farhat MB, et al. (1999). Long term invasive and non invasive results of percutaneous balloon pulmonary valvuloplasty in children, adolescents, and adults. Am HeartJ 138: 950 - 954.
11. Redington AN, Cullen S, Rigby ML (1992). Laser or radiofrequency pulmonary valvotomy in neonates with pulmonary atresia and intact ventricular septum - description of a new method avoiding arterial catheterization. Cardiol Young 2: 387 -390 .

12. Lababidi Z, Wu JR, Walls JT (1984). Percutaneous balloon aortic valvuloplasty: Results in 23 patients. Am JCardiol 53(1): 194-197.

13. Das GS, Radhakrishnan S, Talwar KK, Bahl VK, Rajani M, Shrivastava S (1987). Percutaneous balloon valvuloplasty for valvar aortic stenosis. Indian Heart Journal 39: 146.

14. de Lezo JS, Romero M, Segura J, et al. (2011). Long term outcome of Patients with isolated thin discrete subaortic stenosis treated by Balloon Dilation: A 25 Year Study. Circulation 124: 1461 - 1468.

15. Sos T, Sniderman KW, Rettek-Sos B, et al. (1979). Percutaneous transluminal dilatation of coarctation of thoracic aorta post mortem. Lancet 2: 970-971.

16. Lock JE, Niemi T, Burke BA, et al. (1982). Transcutaneous angioplasty of experimental aortic coarctation. Circulation 66: 1280-1286. 
17. Duggal B, Radhakrishnan S, Mathur A, Khurana P, Shrivastava S (2005). Covered stents deployed for coarctation of aorta with aneurysm. Indian Heart J 57(4): 346-349.

18. Redington AN, Hayes AM, Ho SY (1993). Transcatheter stent implantation to treat aortic coarctation in infancy. Br Heart $J 69$ (1): $80-82$.

19. Zabal C, Attie F, Rosas M, et al. (2003). The adult patient with native coarctation of the aorta: Balloon angioplasty or primary stenting? Heart 89: 77-83.

20. Mullins CE, O'Laughmin MP, Vick GW III, et al. (1988). Implantation of balloon-expandable intravascular grafts by catheterization in pulmonary arteries and systemic veins. Circulation 77: 188-199.

21. Cambier PA, Kirby WC, Wortham DC, et al. (1992). Percutaneous closure of the small (less than 2.5 $\mathrm{mm})$ patent ductus arteriosus using coil Embolization. Am J Cardiol 69: $815-816$.

22. Shrivastava S, Radhakrishnan S, Kapoor A, Jain S (1994). Percutaneous closure of Patent Ductus Arteriosus with Coil. Brief report. Indian Heart J 46: 349-350.

23. Shrivastava S, Marwah A, Radhakrishnan S( 20000$)$. Transcatheter closure of PDA. Indian Pediatrics 37: 1307-1313.
24. Marwah A, Radhakrishnan S, Shrivastava S (2000). Non surgical closure of moderate to large patent arterial duct using the Amplatzer duct occluder. Cardiology in Young 10 : $208-211$.

25. Masura J, Walsh KP, Thamopoulous B, et al. (1998). Catheter closure of moderate to large sized patent ductus arteriosus using the new Amplatzer duct occluder: Immediate and shortterm results. J Am Coll Cardiol 31: $878-882$.

26. Radhakrishnan S, Marwah A, Shrivastava S (2000). Non surgical closure of atrial septal defect using Amplatzer septal occluder in Children - Feasibility and early results. Indian Pediatrics 37: 1181 1187.

27. Masura J, Gavora P, Formanek A, et al. (1997). Transcatheter closure of secundum atrial septal defects using the new self-centering Amplatzer septal occluder; Initial human experience. Cathet Cardiovasc Diagn 42: 388-393.

28. Berger F, Ewert P, Abdul-Khaliq H, et al. (2001). Percutaneous closure of large atrial septal defects with the Amplatzer Septal Occluder: Technical overkill or recommendable alternative treatment? J Interv Cardiol 14: 63-67. 
29. Masura J, Gavora P, Podnar T (2003). Long-term outcome of transcatheter secundum-type atrial septal defect closure using Amplatzer septal occluders. J Am Coll Cardiol 45 : 505-507.

30. Fischer G, Stieh J, Uebing A, et al. (2003). Experience with transcatheter closure of secundum atrial septal defects using the Amplatzer septal occluder: A Single centre study in 236 consecutive patients. Heart 89: 199-204.

31. Thanopoulos BD, Tsaousis GS, Konstadopoulou GN, et al. (1999). Transcatheter closure of muscular ventricular septal defects with the Amplatzer ventricular septal defect occlude: Initial clinical applications in children. $\mathrm{J} \mathrm{Am} \mathrm{Coll} \mathrm{Cardiol} \mathrm{33:}$ $1395-1399$.

32. Holzer R, Balzer D, Cao QL, et al. (2004). Amplatzer Muscular Ventricular septal defect Investigators. Device closure of muscular ventricular septal defects using the Amplatzer muscular ventricular septal defect occluder: Immediate and mid-term results of a U.S. registry. J Am Coll Cardiol 43: $1257-1263$.

33. VSD Device Closure. Quek SC et al. PCSI Boston Abst No. 5169: 7, 2011.

34. Holzer R, Balzer D, Amin Z, et al. (2004). Transcatheter closure of postinfarction ventricular septal defects using the new Amplatzer muscular VSD occluder: Results of a U.S. Registry. Cathet Cardiovasc Interv 61: 196-201.

35. Goldstein JA, Casserly IP, Balzer DT, et al. (2003). Transcatheter closure of recurrent postmyocardial infarction ventricular septal defects utilizing the Amplatzer post infarction VSD device: A case series. Cathet Cardiovasc Interv 59: 238-243.

36. Perry SB, Radtke W, Fellow KE, et al. (1989). Coil Embolization to occlude aortopulmonary collateral vessels and shunts in patients with congenital heart disease. J Am Coll Cardiol 13: 100-108.

37. Wallace S, Gianturco C, Anderson $\mathrm{JH}$, et al. (1976). Therapeutic vascular occlusion utilizing steel coil technique: Clinical applications. AJR Am JRoentgenol 127: 381-387.

38. Abidin N, Clarke B, Khattar RS (2005). Percutaneous closure of ruptured sinus of Valsalva aneurysm using an Amplatzer occlude device. Heart 91: 244.

39. Bialkowski J, Zabal C, Szkutnik M, Montes JA, Kusa J, Zembala M (2005). Percutaneous Interventional Closure of Large Pulmonary Arteriovenous Fistulas with the Amplatzer Duct Occluder. Am J Cardiol 96: 127-129. 
40. Liau CS, Wang JK, Wu MH, Chu IT (1997). Transcatheter closure of a huge pulmonary arteriovenous fistula with Embolization coils. Cathet Cardiovasc Diagn. 42 (3): 286-289.

41. Dorros G, Thota V, Ramireddy K, Joseph G (1999). Catheter based techniques for closure of coronary fistulae. Catheter Cardiovasc Inter 46(2): $143-150$.

42. Behera SK, Danon S, Levi DS, Moore JW (2006). Transcatheter closure of coronary artery fistulae using the Amplatzer Duct Occluder. Catheter Cardiovasc Interv $\mathbf{6 8}$ (2): 242-248.

43. Bhole V, Miller P, Mehta C, Stumper O, Reinhardt Z, De Giovanni JV (2009). Clinical Evaluation of the New Amplatzer Duct Occluder II for Patent Arterial Duct Occlusion. Catheter Cardiovasc Interv 74: 762 769.
44. Tarek S. Momenah, Reida El Oakley, Khalid Al Najashi, Saad Khoshhal, Howaida, Al Qethamy, Philipp Bonhoeffer (2009). Extended Application of Percutaneous Pulmonary valve Implantation. $J$ Am Coll Cardio 53: A28.

45. Kothari SS, Ramakrishnan S, Senguttuvan NB, Gupta SK, Bisoi AK (2011). Ductal recanalization and stenting for late presenters with TGA intact ventricular septum. Ann Ped Cardiol 4: 135-138.

46. Sallehuddin A, Mesned AR, Barakati M, Fayyadh MA, AlFadley F, AlHalees ZY (2007). Fontan Completion without surgery. Eur $J$ Cardio-thoracic Surgery 32: 195200.

47. Ed Sievert H, Qureshi SA, Wilson M, Hijazi ZM (2007). Fetal Cardiac Interventions in Percutanous Interventions for congenital heart disease. Informa UK p.131-134. 